\title{
Maturidade em gestão de projetos em pequenas empresas desenvolvedoras de software do Polo de Alta Tecnologia de São Carlos
}

\author{
Maturity project management in small software \\ development firm's of the Technological Pole of São Carlos
}

\author{
Antonio da Silva Jucá Junior ${ }^{1}$ \\ Edivandro Carlos Conforto² \\ Daniel Capaldo Amaral ${ }^{2}$
}

\begin{abstract}
Resumo: Este artigo analisa o nível de maturidade em gestão de projetos de pequenas empresas desenvolvedoras de software, pertencentes ao polo tecnológico de São Carlos. Por meio de estudo de casos múltiplos, de caráter exploratório-descritivo, descrevem-se o grau de maturidade em gestão de projetos das empresas, suas práticas e problemas enfrentados. Foram analisadas cinco (5) empresas e os resultados indicam estágios iniciais de maturidade em gestão de projetos, baixos níveis de formalização das atividades, ausência de gestão de riscos e comunicação informal na equipe de projeto. A principal contribuição é a comparação entre níveis de maturidade e os problemas enfrentados pelos gestores. Revela um indício empírico da inadequação dos modelos de maturidade para a realidade de empresas similares às estudadas.
\end{abstract}

Palavras-chave: Gestão de projetos. Modelos de maturidade. Empresa de base tecnológica. Software. Desenvolvimento de produtos.

\begin{abstract}
This paper aims to analyze the project management maturity level of small development software companies in the High-Tech Enterprise Center of São Carlos. The project management maturity level of these companies is presented through exploratory-descriptive research and multiple case studies, followed by a discussion of their project management practices. Five firms were analyzed and the results demonstrate the initial stages in project maturity, low formal activities level, and the lack of a consistent risk management, although they have presented good informal communication level between the project members. These findings indicate the need for further research, development and application of effective project management techniques and tools, in order to explore the high level of informal communication, even adapting maturity models for this specific business environment.
\end{abstract}

Keywords: Project management. Maturity model. Technology based firms. Software. Product development.

\section{Introdução}

Pequenas empresas são organizações formadas por um conjunto reduzido de funcionários, comumente lideradas pela figura de um empreendedor visionário e responsável pela criação do negócio. Segundo Kruglianskas, Rimoli e Sbragia (1996), estas empresas apresentam certas características comuns como: capacidade produtiva limitada, ausência de economias de escala, poder de barganha limitado, bem como a heterogeneidade de suas necessidades, que as colocam em situação de possível desvantagem competitiva.
No conjunto de pequenas empresas, algumas se destacam devido ao alto valor tecnológico. Pode-se identificá-las pelo conteúdo tecnológico inserido em seus produtos e serviços (MARCOVITCH; SANTOS; DUTRA, 1986) ou no nível de capacitação, isto é, a existência de uma competência rara ou exclusiva em termos de produtos ou processos, comercialmente viáveis, e que incorporam grau elevado de conhecimento científico (TORKOMIAN; FERRO, 1988; TORKOMIAN, 1996). A este conjunto

\footnotetext{
${ }^{1}$ Mestre em Engenharia de Produção, Programa de Pós-Graduação em Engenharia de Produção, Departamento de Engenharia de Produção, Escola de Engenharia de São Carlos - EESC, Rua São Gabriel, 1855, Apto. 31, Bloco A, Bairro São Vito, CEP 13473-000, Americana - SP, Brasil, E-mail: antonio.juca@gmail.com

${ }^{2}$ Mestre em Engenharia de Produção e Doutor em Engenharia Mecânica, Programa de Pós-Graduação em Engenharia de Produção, Grupo de Engenharia Integrada (EI2), Instituto Fábrica do Milênio (IFM), Departamento de Engenharia de Produção, Escola de Engenharia de São Carlos - EESC, Universidade de São Paulo - USP, Av. do Trabalhador São-carlense, 400, CEP 13566-590, São Carlos - SP, Brasil, E-mails: econfort@ sc.usp.br; amaral@sc.usp.br
} 
de empresas, geralmente encontradas em setores como informática, biotecnologia, robótica, telecomunicações e desenvolvimento de novos materiais, dá-se o nome de empresa de base tecnológica, conhecidas também pela sigla EBT (TORKOMIAN; FERRO, 1988).

Um dos aspectos que diferenciam as pequenas EBTs do ponto de vista do desenvolvimento econômico e social é o papel que desempenham na geração de inovações. Isto é, nem toda pequena empresa desenvolve nova tecnologia ou atua em negócios em que o desenvolvimento de produtos é essencial, porém, parte significativa do universo de empresas inovadoras é formada por pequenas empresas com este perfil.

Tether (1998) apresenta levantamento realizado no Reino Unido, no qual as pequenas empresas tiveram um impacto mais significativo do que as grandes na produção de inovações tecnológicas. Outras medições indicam resultados semelhantes em diversos países, Tsai e Wang (2005) apresentam um compêndio dos trabalhos sobre o tema. Mais recentemente, considerando o número de citações como medida de qualidade, Hicks e Hedge (2005) demonstraram que além de responderem por uma fração importante da inovação, produzem patentes mais significativas

Foram também realizadas buscas na literatura sobre gestão de projetos e gestão de desenvolvimento de produtos, resumidas também no item 3 . Há poucos estudos investigando as práticas e dificuldades na gestão de projetos específicas dessas empresas. Quanto à literatura sobre inovação tecnológica, identificou-se como foco principal o desempenho em inovação e fatores que condicionam este desempenho.

Analisando o resultado desses trabalhos, obtêm-se as seguintes conclusões: 1) o empreendedor (proprietário) é geralmente o elemento principal em termos de domínio do conhecimento e direcionamento da inovação; 2) a sua atuação é fundamental para o resultado final do projeto de desenvolvimento da tecnologia ou produto; 3) o aumento da empresa pode significar diminuição do nível de inovação e uma das hipóteses pode ser o crescimento da complexidade dos projetos; 4) a melhoria e a introdução de práticas de gestão de projetos podem trazer benefícios a estas empresas em termos de resultado da inovação.

Portanto, estudar a aplicabilidade da teoria da gestão de projetos nas pequenas empresas de base tecnológica é algo fundamental não apenas pela sua importância econômica. As características específicas de informalidade, restrição de recursos, colaboração e papel do empreendedor, entre outras que condicionam sua gestão, são desafios a serem vencidos.

Com o intuito de aprofundar-se no tema, este trabalho investiga as práticas de gerenciamento de projetos em empresas de software que fazem parte do Polo de Alta Tecnologia de São Carlos.
Optou-se por empresas do setor de software por tratar-se de um segmento em que a gestão de projetos apresenta um caráter especialmente importante: é intensivo em recursos humanos; o mercado, empresas clientes, costuma exigir práticas avançadas na área; e os produtos do segmento são informações (altos níveis de colaboração e interação e projetos significativamente complexos) (PREESMAN, 2002).

Para avaliar e discutir as práticas, empregou-se o conceito de maturidade de gestão de projetos. $\mathrm{O}$ trabalho avalia o nível de maturidade de um conjunto de empresas, por meio do levantamento sistemático das práticas de gestão de projetos. Ao final, faz-se uma análise teórica do potencial de aplicação do conceito de gestão de projetos nestas empresas.

\section{Pequena empresa de base tecnológica}

Uma classificação de empresas de base tecnológica, mais recente, é a proposta por Jong e Marsili (2006), baseada em dados empíricos de um questionário aplicado por telefone em 2985 empresas holandesas, aleatoriamente escolhidas. Classificam as PMEs em quatro tipos; um deles se enquadra no conceito de base tecnológica (science-based). Segundo este estudo, as características de uma empresa de base tecnológica são: comercializar produtos de alta densidade tecnológica, proporção significativa de colaboradores altamente capacitados; possuir proporção significativa dos investimentos em Pesquisa e Desenvolvimento; utilização de fontes externas como universidades e clientes; foco gerencial para a inovação; e nível elevado de colaboração.

Acs e Audrestch (1992) explicam a vantagem destas empresas no fato de serem capazes de absorver maior risco, permitindo-lhes a entrada em nichos de mercado com potencial de inovação elevado. Rothwell e Dodgson (1992) argumentam no mesmo sentido, adicionando a facilidade de acesso às fontes de inovação, tais como fornecedores e clientes, estruturas organizacionais mais flexíveis e capacidade de buscar novas competências rapidamente. Levistky (1996), Lemos (1999), Candido e Dias, (1998) e Nowak e Granthan (2000) confirmam as características apresentadas nestes estudos e adicionam a importância do papel do empreendedor visionário e da estrutura organizacional enxuta.

Segundo Porter (1998), tais empresas apresentam maior potencial para geração de valor e as nações mais competitivas incentivam sua formação. Por isso, encontram-se comumente inseridas em ambientes institucionais compostos por outros agentes ligados à rede de ciência e tecnologia: universidades, incubadoras, clusters, instituições de fomento, polos tecnológicos e empresas de capital de risco. 
Não há dúvidas, portanto, sobre a importância destas empresas para o desenvolvimento econômico. Só para citar outro aspecto, Sterlacchin (1999), analisando dados de empresas italianas, e Knight (2001), empresas americanas, demonstram que as pequenas empresas com maior sucesso são as que geram novos produtos e tecnologias.

\section{Gestão de projetos em pequenas empresas de base tecnológica}

Starbek e Grum (2002) descrevem uma intervenção em uma pequena empresa Eslovena de implementos agrícolas com o intuito de reestruturar o desenvolvimento de novos produtos (DP). Organizando-a em times e adotando práticas de gestão de projetos, demonstram que é possível adaptar as técnicas tradicionais de gestão de projetos nestas empresas.

Há, porém, obstáculos típicos desse tipo de empresa. March-Chordà, Gunasekaran e Lloria-Aramburo (2002) identificaram, por meio do levantamento da percepção dos gestores de DP em PMEs, as seguintes barreiras: desestímulo decorrente do alto ciclo de vida dos produtos (o que pode ser relacionado com a tendência em planejar a curto prazo); custo elevado associado a projetos de inovação; e falta de capacidade para o desenvolvimento de projetos complexos de DP.

Tsai e Wang (2005) compilaram trabalhos descrevendo aspectos positivos e negativos das pequenas empresas se comparadas às grandes em termos de inovação. A principal vantagem das grandes empresas seria a maior quantidade de recursos e melhor estrutura, que permitiriam maior capacidade de coordenar projetos de pesquisa e desenvolvimento complexos; e de gerenciar de maneira mais eficiente portfólios completos de tecnologia. Por outro lado, as pequenas empresas teriam a seu favor maior facilidade e agilidade na obtenção de dados de fontes externas, permitindo-lhes maior eficiência na geração da tecnologia. Eles realizaram um estudo em 126 empresas de manufatura da Coréia para verificar qual seria o mecanismo mais vantajoso. Os resultados indicaram uma tendência de curva em "U" na relação tamanho da empresa e eficiência na inovação. Isto significaria que até determinado tamanho as pequenas empresas seriam mais produtivas que as grandes, o crescimento levaria a uma região de baixa eficiência e retorno ao patamar de maior eficiência.

$\mathrm{O}$ mecanismo que pode explicar estes resultados seriam as dificuldades gerenciais, crescentes conforme a empresa aumenta de tamanho. Man, Lau e Chan (2002) demonstram evidências de que a distinção entre o sucesso e o fracasso de pequenas empresas está fortemente relacionada com a experiência, conhecimento e habilidades dos proprietários. No Brasil, Rieg e Alves Filho (2003) e Jugend (2006) identificam resultados semelhantes. Weterings e Koster (2007), estudando empresas holandesas da área de software, observaram que experiências anteriores como empreendedor e de gestão têm impactos positivos no nível de inovação das empresas, com vantagens para a experiência como empreendedor; mais significativa que a de profissional. O trabalho de Nowak e Grantham (2000) aponta para direção semelhante. Analisando um programa da NASA de apoio à inovação por meio de pequenas empresas de alta tecnologia, os autores afirmam que tais parcerias funcionam melhor especialmente quando acompanhadas de treinamento e acesso às técnicas de negociação e gestão (NOWAK; GRANTHAN, 2000).

Portanto, o papel do empreendedor na gestão eficiente pode ser considerado essencial para o desempenho dos projetos. Porém, poucos estudos abordam a adoção de tecnologias de gestão de maneira mais detalhada. Uma exceção é o trabalho de Calderini e Cantamessa (1997), que analisou 21 empresas de pequeno e médio porte localizadas nos arredores de Turin, Itália. Os autores categorizaram as empresas em três "tipos" em função da estratégia de oferta do produto: (A) empresas que ofereciam produtos de prateleira; (B) empresas oferecendo produtos customizados e competindo por meio de sua capacidade de entregar valor ao mercado; e (C) subcontratados verticalmente integrados com seus clientes (no caso a FIAT). Segundo os autores, as empresas do grupo B apresentavam-se na "fronteira da excelência" na gestão do DP, eram as empresas mais equilibradas em termos de adoção de metodologias e tecnologias de apoio ao projeto de novos produtos. No geral, a adoção de metodologias de gestão era vista como "perda de tempo" pelos entrevistados, enquanto as ferramentas tecnológicas relacionadas ao DP, como CAD/CAM, CAPP, CAE entre outras, eram fortemente presentes, porém com alto grau de ociosidade. Como resultado, afirmam que a adoção de metodologias ou tecnologias de PDP pode resultar em sucesso e alto retorno por investimento. Para isso, devem estar harmonizadas com a cultura organizacional de gestão de projetos na empresa. Sugerem um processo autoevolutivo no qual a história da construção da prática seja adequada à realidade de cada empresa.

Ali, Krapfel e Labahn (1995) relatam um estudo realizado com proprietários de 73 PMEs de alta tecnologia americanas cujo objetivo foi investigar o impacto do grau de inovação de um produto e sua complexidade técnica no tempo de desenvolvimento (tempo de ciclo) e retorno do investimento. Entre várias observações interessantes destaca-se a relação entre tempo de desenvolvimento e inovação. Contrariando o senso comum, demonstraram que projetos com menor tempo de ciclo resultaram em produtos com maior vantagem intrínseca (melhores frente aos concorrentes). Uma hipótese para explicar este fato pode ser o item 1 de que eles apresentariam níveis menores de 
complexidade. Outra possibilidade citada é o fato de serem projetos prioritários para a organização e que, portanto, tenham recebido tratamento diferenciado no seu planejamento, monitoramento e controle; enfim, gestão mais eficiente.

Os dois últimos trabalhos descrevem uma aparente contradição. De um lado, há o foco nas ferramentas técnicas de DP e as técnicas e métodos de gestão de projetos de desenvolvimento de produtos são vistas como "perda de tempo" (CALDERINI; CANTAMESSA, 1997) pelos empresários do setor; incluem-se as técnicas de gerenciamento de projetos neste contexto. Por outro lado, trabalhos como o de Ali, Krapfel e Labahn (1995), Nowak e Grantham (2000), Man, Lau e Chan (2002) e Weterings e Koster (2007) indicam que técnicas de gestão de projetos poderiam trazer benefícios se aplicadas pelos empreendedores.

Jugend (2006) pesquisou empresas de base tecnológica na área de automação e controle do Estado de São Paulo e encontrou um padrão semelhante ao apresentado até aqui. $\mathrm{O}$ estudo apresenta um levantamento com tratamento estatístico de 10 fatores que afetam o desempenho em inovação, investigando 64 variáveis e aplicando-as em uma amostra de 32 empresas. Identificou que o empreendedor, isto é, o conhecimento acumulado por ele e sua capacidade de liderança, é fundamental para os resultados dos projetos de desenvolvimento de novos produtos. O conhecimento das práticas de gerenciamento de projetos faz parte, portanto, deste fator. $\mathrm{O}$ autor afirma ainda que a falta deste perfil gerencial pode ser um entrave.

Outro aspecto interessante dos dados coletados é que eles captam também a aparente contradição sobre a necessidade ou não de técnicas gerenciais. Quando questionados sobre principais preocupações, os empreendedores não citaram aspectos relacionados à gestão: apenas questões técnicas como dificuldade de importação de componentes eletrônicos, fabricação de moldes e matrizes ou a obtenção de recursos humanos especializados. Entretanto, encabeça a lista de problemas um item denominado "dificuldade de entregar os projetos no prazo previsto", com ocorrência de $17 \%$. E mais, quando questionadas sobre tendências, $10 \%$ das empresas apontaram a gestão de projetos como um dos temas em que se deseja investir; em softwares e treinamento para os funcionários na área. Trata-se do quarto item de maior importância. Portanto, reforça o padrão encontrado por Calderini e Cantamessa (1997) de que os empreendedores não percebem as práticas gerenciais como importantes, apesar de reconhecerem os problemas decorrentes da sua ausência.

Portanto, o resultado deste levantamento bibliográfico demonstra uma ausência de trabalhos e autores que se proponham a estudar detalhes sobre as práticas de gestão de projetos de acordo com a realidade das pequenas empresas de base tecnológica; apesar das pesquisas sobre a inovação indicarem a necessidade de capacitação gerencial, considerada fundamental. A maioria dos trabalhos são levantamentos amplos.

Uma alternativa para se preencher a lacuna é investigando o nível de maturidade em gestão de projetos existentes nas pequenas empresas de base tecnológica, objetivando uma análise de um ponto de vista mais detalhado. No próximo item, discute-se o conceito de maturidade em gestão de projetos.

\section{Maturidade em gestão de projetos}

Define-se maturidade em gestão de projetos como sendo o desenvolvimento de sistemas e processos, conjunto de atividades, de natureza repetitiva e que garantam alta probabilidade de sucesso (KERZNER, 2006). Isso significa atingir um patamar em que as práticas de gestão e controle dos projetos sejam "institucionalizadas" na organização. A execução consistente deixa de depender unicamente da atitude dos profissionais (CRISSIS; KONRAD; SCHRUM, 2003). Deve-se lembrar que processos e sistemas repetitivos ou institucionalizados não são garantias de sucesso, apenas aumentam a probabilidade.

$\mathrm{O}$ conceito de maturidade adquire um aspecto de diagnóstico. Um modelo de maturidade em projetos tem por objetivo, portanto, medir o estágio de organização das empresas na gestão de seus projetos e indicar caminhos para a melhoria desse nível de organização. Tonini, Carvalho e Spinola (2008), em um estudo de casos múltiplos, realizado em empresas de software, demonstram que os modelos de maturidade contribuem como orientadores da melhoria da qualidade. Mais recentemente, Patah e Carvalho (2009) apresentaram dados de cinco empresas comparando o nível de maturidade com o crescimento do lucro, nos quais há evidências de que maiores níveis de maturidade estão relacionados ao melhor desempenho.

Existem várias propostas de modelos de maturidade. Os modelos discutidos neste trabalho foram selecionados por serem os mais comentados, discutidos e estudados na teoria de maturidade e pelos profissionais em gestão de projetos. Incluem-se modelos que, embora não tenham sido exclusivamente desenvolvidos para este fim, podem também auxiliar, são eles o Capability Maturity Model - CMM (SEI, 1997). Deve-se salientar que vários outros modelos não serão discutidos neste trabalho, como US Federal Aviation Administration Integrated Capability Maturity Model (IBRAHIM; LA BRUYERE; WELLS, 2001); Software Process Improvement and Capability dEtermination (SPICE, 200-); Project Management Maturity Model de Knapp \& Moore Pty Ltd. (KNAPP \& MOORE, 200-), entre outros, pelo fato de terem sido elaborados a partir dos modelos principais apresentados na próxima seção e, portanto, possuírem graus elevados de similaridade. Optou-se sempre pelo original e mais difundido. 


\subsection{Capability maturity model}

Um dos pioneiros e mais conhecidos modelos de maturidade e melhoria de processos, o Capability Maturity Model ou CMM foi desenvolvido pelo Software Engineering Institute, instituto ligado ao Carnegie Mellon University (SEI, 1997).

Este modelo é utilizado como base para dezenas de outros modelos de maturidade e seu foco é o processo de desenvolvimento de software, com ênfase nas atividades de definição, especificação e teste. A classificação de maturidade no CMM é dividida em cinco níveis, conforme apresentada no Quadro 1.

Atualmente este modelo evoluiu para o Capability Maturity Model Integration - CMMI. Este modelo é uma síntese do modelo CMM, inicialmente desenvolvido apenas para software, integrado a outros modelos de melhoria desenvolvidos pela SEI, respectivamente para a engenharia de sistemas, engenharia de software, desenvolvimento integrado de produtos e processos e ainda o desenvolvimento de fornecedores. Portanto, o CMMI é voltado para organizações que desenvolvem sistemas (isto é, software e hardware, produtos físicos). Um dos aspectos interessantes do CMMI é que ele é organizado em dois tipos de representações, contínua ou por estágios, de forma que as práticas podem ser organizadas por níveis de maturidade ou áreas de processo (CRISSIS; KONRAD; SCHRUM, 2003). Mais recentemente ainda, este modelo evoluiu para o denominado $C M M I$ for Development (ENGINEERING INSTITUTE - SEI (2006), específico para desenvolvimento de sistemas (produtos, hardware, ou software), separando-o de versões específicas para produtos que são serviços e processos de aquisição.

\subsection{Project management maturity model (Organizational Project Management Maturity Model)}

OPM3 é a sigla do Organizational Project Management Maturity Model, um projeto liderado pelo Project Management Institute que teve início em 1998, com o objetivo de propor um modelo de maturidade genérico. Profissionais de gestão de projetos provenientes de diferentes culturas e tamanhos de empresas contribuíram para a elaboração desse guia.

O modelo OPM3 (2008) propõe um checklist para avaliar o estágio de competência das organizações, apresentando os passos necessários para a evolução em direção a um estágio superior e assim por diante. Divide-se em três áreas e quatro níveis de maturidade, conforme Figura 1.

Para a sua criação, foram realizadas buscas e análises com dezenas de modelos e frameworks sobre as práticas de gestão de projetos. Mais de $30 \mathrm{mil}$ profissionais da área foram consultados por meio de surveys. Antes da construção do modelo, foi reunido um total de 170 melhores práticas em uma pesquisa de campo.

As melhores práticas foram avaliadas segundo os critérios:

- Realmente contribui para a maturidade em gestão de projetos na organização?

- A organização tem condições de implementá-la diretamente, sem a necessidade de pré-requisitos?

- Permitem o uso de critérios de performance como forma de medir a eficiência da implementação?

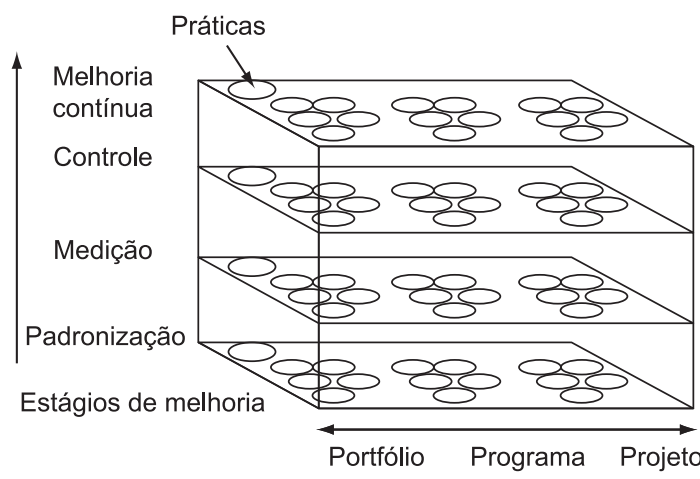

Figura 1. Modelo de Maturidade OPM3. Fonte: PMI (2008); OPM3 (2008).

Quadro 1. Classificação de Maturidade no CMM. Fonte: SEI (1997).

\begin{tabular}{|ll|}
\hline Inicial - primeiro nível & $\begin{array}{l}\text { É caracterizado por um processo de desenvolvimento informal no qual os } \\
\text { projetos habitualmente ultrapassam os prazos e custos originais. }\end{array}$ \\
Repetição - segundo nível & $\begin{array}{l}\text { Os planos desenvolvidos são baseados no passado e, portanto, são mais realistas. } \\
\text { Definição - terceiro nível }\end{array}$ \\
$\begin{array}{l}\text { É marcado pela existência de processos bem definidos, melhorando assim o } \\
\text { desempenho dos projetos. }\end{array}$ \\
Gerência - quarto nível & Os processos e produtos são quantitativamente controlados. \\
Otimização - quinto nível & $\begin{array}{l}\text { A maturidade é consolidada e a gestão de projetos institucionalizada, } \\
\text { possibilitando a criação de um processo de melhoria contínua. }\end{array}$ \\
\hline
\end{tabular}


O estudo do OPM3 (2008) considera três elementos básicos para sua implantação dentro da organização.

Conhecimento: o modelo utiliza seu próprio corpo de conhecimento, PMBOK, como padrão para gestão de projetos, assim, seu modelo de maturidade exige um conhecimento prévio neste padrão já existente.

Avaliação: o modelo oferece uma ferramenta de avaliação que indica pontos fortes e pontos fracos com relação ao corpo de melhores práticas adotado pelo PMI, dessa forma, a empresa decide melhores práticas ou grupo de melhores práticas a serem trabalhadas. Dependendo do resultado da avaliação, a empresa pode optar entre parar ou continuar o processo de melhoria em determinada área.

Melhorias: o modelo, depois de identificadas as melhores práticas a serem alcançadas, disponibiliza um conjunto de "potencialidades", como um checklist, no qual são relacionadas as competências necessárias para cada melhor prática.

Dessa maneira, além de um referencial teórico com conceitos e técnicas já existentes, o OPM3 (2008) possibilita que a empresa identifique internamente as "potencialidades" capazes de levá-la a um estágio mais alto de maturidade, assim o OPM3 (2008) se apresenta como uma forma da empresa utilizar as melhores práticas do setor juntamente com aspectos internos positivos, isso é possível por meio do uso de um autodiagnóstico presente no modelo.

\subsection{Project management maturity model}

Kerzner (2006) propõe a análise da maturidade na gestão de projetos por meio de um modelo com cinco fases conhecido como Project Management Maturity Model. A primeira fase, denominada embrionária, acontece quando as primeiras evidências em gestão de projetos são percebidas pela empresa. A segunda fase refere-se ao reconhecimento da importância em gestão de projetos pela alta administração. A terceira fase, ao reconhecimento das necessidades em gestão de projetos pela linha gerencial da empresa. A quarta fase corresponde ao crescimento da função de gestão de projetos. A última fase corresponde à maturidade organizacional em projetos (KERZNER, 2006).

O modelo de Kerzner possui uma representação de níveis e seu diagnóstico é realizado a partir de um questionário com 183 questões disponíveis em uma ferramenta baseada na WEB, que, ao serem devidamente respondidas, indicam o nível de maturidade em que se encontra a organização nas práticas de gestão de projetos.

\subsection{ESI Maturity Model}

Em 1999, o ESI International lançou o seu modelo de maturidade aplicado à gestão de projetos.
Denominado Project FRAMEWORK, seu objetivo é o aperfeiçoamento contínuo da gestão de projetos nas organizações, pela integração de pessoas, processos e tecnologia.

O Project FRAMEWORK propõe apoiar as organizações: identificando pontos fortes e fracos no processo de gestão de projetos; estabelecendo uma referência na capacitação em gerência de projetos; tornando-se orientado a projetos e com resultados mais previsíveis; lançando um programa de melhoria contínua; e integrando princípios e processos de gestão eficaz de projetos na estrutura e nos processos organizacionais.

O modelo do ESI incorporou as ideias de progressividade e de níveis de maturidade do modelo CMM, cuja aplicação restringe-se às organizações que desenvolvem software, ao mesmo tempo em que trata detalhadamente as práticas descritas nos nove campos de conhecimento no PMBOK, definindo objetivos de desempenho para cada um deles.

\subsection{Modelo de maturidade segundo Rabechini}

Este modelo foi proposto por pesquisadores da Universidade de São Paulo em 2002, após analisarem diversos modelos de maturidade e casos reais em empresas. Nestes questionários, os autores incorporaram indicadores relativos às quatro dimensões principais da competência e da maturidade: estratégia, estrutura, processos e comportamento (RABECHINI JUNIOR, 2003; RABECHINI JUNIOR; MAXIMIANO, 2002). O diferencial é considerar aspectos como estratégia, não tratados pelos outros modelos. A desvantagem é o nível de abstração maior e menor detalhamento das práticas.

\section{Método}

\subsection{Delineamento da pesquisa}

O método utilizado foi a pesquisa de caráter exploratório-descritiva com estudo de casos múltiplos, segundo Yin (2001). A pesquisa exploratória visa desbravar novas áreas do conhecimento e construir hipóteses; e as descritivas preocupam-se em descrever um fenômeno (GIL, 1991). O interesse em entender detalhes das práticas em si conduziu a essas escolhas. Segundo Eisenhardt (1989) e Yin (2001), o estudo de caso permite entender a dinâmica presente em unidades organizacionais, pode envolver um único caso como também casos múltiplos e diferentes níveis de análise.

Empregou-se um modelo de maturidade em gestão de projetos existente, dado que a pesquisa não se propõe a pesquisar a teoria de modelos de maturidade e sim aplicá-la aos problemas de gestão de projetos das empresas de base tecnológica. 


\subsection{Unidade de análise}

A unidade de análise é o setor de desenvolvimento de software de cada empresa. Portanto, pode-se classificá-lo também como um estudo holístico na acepção de Yin (2001). Avaliou-se, em cada caso, o nível de maturidade em gestão de projetos, conforme o modelo teórico OPM3 adaptado.

\subsection{Modelo teórico para avaliação do nível de maturidade}

Os principais modelos de maturidade em GP, citados na revisão bibliográfica (RABECHINI JUNIOR, 2003; RABECHINI JUNIOR; MAXIMILIANO, 2002; CMMI, 2002; KERZNER, 2006; SEI, 1999; OPM3, 2008) foram comparados. Como resultado, optou-se pelo OPM3 que, apesar de ser um modelo recente e por isso ainda não testado e validado como outros modelos mais consolidados, possuía, na época da pesquisa, escopo exclusivo nas práticas do gerenciamento de projetos, mais ligado, portanto, à necessidade do trabalho. Os motivos que justificam a decisão estão descritos no Quadro 2.

Conforme apresentado no item 4.2, o modelo OPM3 (2008) propõe um checklist de práticas, agrupadas em portfólio, programa e projeto. Ao final da análise, considerou-se o checkist proposto demasiadamente extenso para o uso na pesquisa e a necessidade de adaptá-lo tornou-se evidente. Desenvolveu-se, então, um modelo de avaliação adaptado e reduzido que atendesse aos objetivos do OPM3. Ele foi construído por meio de agrupamento das questões presentes no roteiro inicial. Elas foram transcritas de forma resumida, sem prejuízo do conteúdo. Ao final desta tarefa obteve-se uma lista de práticas menores que o modelo original do OPM3, porém coerentes.

Quadro 2. Motivos para a escolha do modelo de maturidade.

- O foco principal é a gestão de projetos, ao contrário de modelos como CMMI cujo foco é mais amplo, desenvolvimento de produtos.

- Foi elaborado a partir da contribuição de milhares de profissionais da área de gerenciamento de projetos.

- O instituto que liderou a sua elaboração é um agente que fomenta a construção de conhecimento na área de gestão de projetos, garante-se coesão dentro do vocabulário e conceitos utilizados entre o modelo e a teoria de gestão de projetos já existente.

- Modelo trabalha exclusivamente com melhores práticas da gestão de projetos e não aborda outros temas como o desenvolvimento de produtos (como o CMMI) ou a estratégia da organização (RABECHINI JUNIOR, 2003; RABECHINI JUNIOR; MAXIMILIANO, 2002).

\subsection{Instrumentos de coleta de dados}

Com o intuito de alcançar o nível de detalhe esperado de acordo com os objetivos da pesquisa, empregaram-se dois instrumentos de coleta de dados complementares: 1) a entrevista semiestruturada norteada por pautas, permitindo certa flexibilidade, mas garantindo profundidade na análise; e 2) observação direta do pesquisador durante o estudo de campo.

Foram elaborados um roteiro de observações e um roteiro de entrevistas. Ambos utilizaram como origem a lista de práticas sintetizadas. Outra mudança foi o agrupamento das práticas em áreas, tendo-se como referência as áreas do PMBoK (PMBoK, 2008), com adaptações. As categorias utilizadas foram: iniciação do projeto; integração; escopo; atividades; pessoas; custos; riscos; qualidade; aquisição; técnicas e ferramentas; e ambiente do projeto.

O roteiro de observações descreve itens a serem observados pelo pesquisador durante o trabalho de campo. O pesquisador registrou informações sobre cada um dos tópicos presentes neste roteiro durante todos os momentos em que entrava em contato com a empresa.

O roteiro de entrevista foi elaborado na forma de questões. Exemplificando, as melhores práticas sobre o papel do gerente de projetos descrevem as atividades e responsabilidades deste durante o projeto: (a) estabelecimento do papel e responsabilidades do gerente de projeto; (b) contribuição e relevância das decisões do gerente de projeto no escopo do projeto. Partiu-se para a identificação de questões que permitissem descrevê-las, obtendo-se:

Q1 Todo projeto da empresa possui um gerente de projeto nomeado?

Q2 Quais são as responsabilidades esperadas de um gerente de projeto? Como estas responsabilidades são cobradas? Elas são formalizadas/documentadas?

Q3 Como é feita a nomeação dos gerentes de projeto?

As questões foram agrupadas por práticas e as práticas nas categorias descritas anteriormente. As respostas das questões e observações de uma mesma prática foram utilizadas para identificar um nível correspondente a ela. Empregou-se a mesma classificação de níveis proposta pelo CMMI, com adaptações. Os níveis são apresentados na Tabela 1 .

\subsection{Escolha dos casos}

A escolha dos casos foi intencional visando reunir três condições: tratar-se de pequena empresa pertencente ao Polo Tecnológico de São Carlos, atuar no setor de software e possuir características comuns às empresas de base tecnológica. 
O único objetivo não plenamente atingido é o caráter Empresa de Base Tecnológica. No polo em questão havia empresas com infraestrutura e investimentos significativos em desenvolvimento de produtos, relacionamento estreito com universidades e centros de pesquisas e demais características típicas de uma empresa de base tecnológica, considerando o trabalho de Jong e Marsili (2006). Poucas delas, porém, possuíam produtos com alta densidade tecnológica, isto é, com componentes que representem fronteiras do conhecimento. Optou-se então por eliminar este último critério, de forma a incluir também empresas cujos produtos, apesar de complexos e exigirem alta qualificação para o seu desenvolvimento, não poderiam figurar necessariamente como inovadores para o mercado. Um resumo dos critérios utilizados é descrito no Quadro 3.

O Quadro 4 apresenta uma breve descrição das empresas escolhidas para fazer parte do estudo.

Ressalta-se que, apesar das empresas escolhidas não possuírem todas as condições definidas por Jong e Marsili (2006) para serem consideradas de base tecnológica, acredita-se que podem servir ao propósito da pesquisa por caracterizarem-se como empresas que utilizam competências raras, intensivas em conhecimento e com o foco em desenvolvimento.

\subsection{Coleta de dados}

A fase de coleta de dados aconteceu no período de 4 meses. O pesquisador entrou em contato com as empresas e solicitou acesso por um período curto de tempo. Despendeu um tempo entre 3 dias e uma semana em cada empresa, período durante o qual realizou anotações sobre suas percepções seguindo os itens do roteiro de observações.

\subsection{Análise dos resultados}

Os resultados das entrevistas e observações foram compilados por meio de análise qualitativa em categorias. Gerou-se um relatório intermediário para cada caso com resumo das observações e respostas por meio de frases representativas. Em um segundo momento, o conjunto de frases relacionado a cada prática era avaliado e, com base nos conceitos teóricos,

Tabela 1. Valor associado a cada nível de maturidade.

\begin{tabular}{cc}
\hline Nível de maturidade & Valor associado \\
\hline Não acontece & 0 \\
Ad-hoc & 1 \\
Padronizado & 2 \\
Medido & 3 \\
Controlado & 4 \\
Melhorado & 5 \\
\hline
\end{tabular}

atribuíram-se valores, conforme a Tabela 2, para o nível de maturidade de cada prática.

O procedimento permitiu, em uma terceira etapa, identificar o nível de maturidade por categoria, calculando-o pelo valor médio de cada prática pertencente a uma mesma categoria. Quando todo o grupo de práticas de uma determinada área de conhecimento for realizado de maneira "Melhorado", o que significa pelo modelo utilizado o nível mais alto de pontuação, toda a área de conhecimento possui pontuação máxima, ou 100\%.

\section{Resultados de cada caso}

Na Tabela 3, apresenta-se o resultado final da análise em termos de porcentagem geral de nível de maturidade e, a seguir, breve descrição da situação verificada em cada empresa.

\subsection{Empresa A}

A empresa A apresentou pontuação em todas as áreas de conhecimento com exceção da área de gerenciamento de riscos dos projetos. Merece destaque a área de gerenciamento de tempo, ou atividades, para a qual havia desenvolvido procedimentos e ferramentas de controle dos projetos, isto é refletido na pontuação verificada no item gerenciamento das atividades, com a marca de $53 \%$.

Durante o estudo, realizava um conjunto de ações no sentido de melhorar atividades e implantar outras que inexistiam no momento do diagnóstico. Utilizava um recurso da própria empresa que havia recentemente assumido o papel de facilitador interno, para fomentar mudanças na gestão de projetos. Merece destaque o comprometimento da diretoria da empresa com os trabalhos realizados; por meio de reuniões, debatiam as propostas de melhoria.

A empresa possuía duas equipes de projeto, e esta avaliação foi realizada dentro de uma das equipes voltadas a nichos distintos. O trabalho avaliou uma dessas unidades, não representando, portanto, o cenário global em termos de gerenciamento de projetos.

\subsection{Empresa B}

De maneira análoga à anterior, a empresa $\mathrm{B}$ também não apresentou prática de gerenciamento de riscos do projeto. Embora em menor grau, destacaram-se as práticas de inicialização do projeto e de gerenciamento de atividades e pessoas, atingindo pontuação de 40 , 33 e $33 \%$, respectivamente.

Analisando o comportamento geral de todas as práticas diagnosticadas, nota-se que $70 \%$ das atividades não existiam ou eram executadas de maneira particular para cada projeto e pouco estruturadas. Esta empresa encontrava-se em um momento de buscar ferramentas de 
Quadro 3. Critérios para a escolha dos casos a serem estudados.

\begin{tabular}{|c|c|}
\hline Critério & Comentários \\
\hline Ser classificada como pequena empresa. & $\begin{array}{l}\text { Número de funcionários e faturamento compatíveis com } \\
\text { a classificação de pequena empresa do SEBRAE. }\end{array}$ \\
\hline Atuar no ramo de desenvolvimento de software. & $\begin{array}{l}\text { Por tratar-se de um setor econômico com alta exigência } \\
\text { quanto ao nível de gestão de projetos. }\end{array}$ \\
\hline $\begin{array}{l}\text { Possuir projetos de DP e/ou tecnologias, com } \\
\text { níveis mínimos de complexidade e representativos } \\
\text { (investimentos significativos em pesquisa ou } \\
\text { desenvolvimento de novos produtos) }\end{array}$ & $\begin{array}{l}\text { O nível mínimo foi avaliado como um conjunto de } \\
\text { tarefas, duração e tamanho de equipe suficiente para se } \\
\text { justificar a necessidade de métodos e ferramentas para o } \\
\text { gerenciamento de projetos. }\end{array}$ \\
\hline Participar do Polo de Alta Tecnologia de São Carlos. & $\begin{array}{l}\text { Proximidade física, projetos executados em conjunto, } \\
\text { relacionamento interpessoal. Além de serem do polo de } \\
\text { alta tecnologia. }\end{array}$ \\
\hline Possuir colaboradores capacitados. & $\begin{array}{l}\text { A maioria dos funcionários de desenvolvimento deve } \\
\text { possuir } 3^{\circ} \text {. Grau e incluir um ou mais pós-graduandos. }\end{array}$ \\
\hline Colaboração com universidades e centros de pesquisa. & $\begin{array}{l}\text { Possuir projetos conjuntos ou outro tipo de parceria } \\
\text { com universidades ou centros de pesquisa. }\end{array}$ \\
\hline
\end{tabular}

Tabela 2. Relação entre valores gerais obtidos por categoria e nível de maturidade.

\begin{tabular}{ccccccc}
\hline Nível Associado & Inexistente & Ad-hoc & Padronizado & Medido & Controlado & Melhorado \\
\hline Faixa de valores (\%) & $0-20$ & $21-40$ & $41-60$ & $61-80$ & $81-90$ & $91-100$ \\
\hline
\end{tabular}

apoio às atividades de gerenciamento de projetos, além de participar de cursos de gerenciamento de projetos.

\subsection{Empresa C}

A empresa $\mathrm{C}$, apesar de não apresentar nenhuma prática diagnosticada para o gerenciamento de riscos do projeto, como as demais já estudadas, possui uma das maiores pontuações em termos de práticas para o gerenciamento de custos do projeto. A motivação disso é a sua trajetória. Por atravessar dificuldades financeiras em períodos anteriores à pesquisa, desenvolveu sistemáticas avançadas de controle de custos dos projetos.

Vale observar ainda que a empresa $\mathrm{C}$, dentro do universo de empresas analisadas, foi a que possuiu menos atividades enquadradas como "Inexistentes" ou "Ad-hoc"; apresentando 29\% das atividades diagnosticadas como "Padronizadas".

\subsection{Empresa D}

A empresa D apresentou uma elevada pontuação em relação às demais nas práticas voltadas para o gerenciamento de custos do projeto. Entretanto, apresentou a menor pontuação das práticas classificadas como "Técnicas e ferramentas".

Observa-se ainda que, dentro do grupo de empresas entrevistadas, a empresa D foi a que apresentou a
Tabela 3. Resultados da pesquisa, por nível de maturidade das atividades.

\begin{tabular}{lrrrrr}
\hline & A & B & C & D & E \\
\hline Não acontece & $38 \%$ & $37 \%$ & $37 \%$ & $40 \%$ & $37 \%$ \\
Ad-hoc & $27 \%$ & $33 \%$ & $27 \%$ & $29 \%$ & $31 \%$ \\
Padronizado & $21 \%$ & $23 \%$ & $29 \%$ & $29 \%$ & $25 \%$ \\
Medido & $12 \%$ & $6 \%$ & $4 \%$ & $2 \%$ & $2 \%$ \\
Controlado & $0 \%$ & $0 \%$ & $0 \%$ & $0 \%$ & $0 \%$ \\
Melhorado & $2 \%$ & $2 \%$ & $4 \%$ & $0 \%$ & $6 \%$ \\
\hline
\end{tabular}

maior quantidade de práticas diagnosticadas como "Inexistentes".

\subsection{Empresa E}

$\mathrm{Na}$ empresa $\mathrm{E}$, como em todas as demais, não foram identificadas práticas de gerenciamento de riscos. Entretanto, esta empresa apresentou a maior pontuação dentro do grupo de práticas denominadas de "Técnicas e Ferramentas", isto se deve ao fato da empresa utilizar, de maneira efetiva e para todos os projetos, ferramentas de comunicação e procedimentos de documentação de lições aprendidas.

Devido à incidência de práticas voltadas a coletar e registrar as lições aprendidas dos projetos da empresa E, esta apresentou o maior grupo de atividades diagnosticadas dentro do nível de "Melhorado". A Tabela 3 apresenta uma visão por nível de prática. 
Quadro 4. Descrição das empresas analisadas no estudo de caso.

\begin{tabular}{|c|c|}
\hline Empresa A & $\begin{array}{l}\text { - É uma empresa de software que desenvolve projetos e aplicações para WEB; } \\
\text { - Possui uma estrutura organizacional do tipo projetizada; } \\
\text { - Possui duas grandes áreas de desenvolvimento de produtos: a) voltada para o desenvolvimento } \\
\text { de aplicações baseadas em plataformas e componentes de software livre; b) utiliza plataforma de } \\
\text { desenvolvimento fechada, e que na fase de coleta de dados não foram evidenciadas as práticas de } \\
\text { gerenciamento de projetos adotadas por esta equipe; e } \\
\text { - Relacionamentos com a Universidade de São Paulo e Universidade Federal de São Carlos. }\end{array}$ \\
\hline Empresa B & $\begin{array}{l}\text { - É uma empresa de tecnologia voltada para o ramo agroindustrial especializada em automação } \\
\text { agrícola; } \\
\text { - Possui estrutura organizacional do tipo matricial forte; e } \\
\text { - Forte vínculo com a Embrapa Instrumentação Agropecuária. }\end{array}$ \\
\hline Empresa C & $\begin{array}{l}\text { - Atua com serviços de consultoria e desenvolve tecnologia na área de controle de acessos de pessoas } \\
\text { para o mercado corporativo; } \\
\text { - Seus produtos são baseados em tecnologia desenvolvida internamente e são utilizados por grandes } \\
\text { empresas de diferentes segmentos; } \\
\text { - Possui uma estrutura organizacional matricial forte, onde as equipes de projeto possuem um líder } \\
\text { de projeto que direciona a equipe e gerencia as diferentes etapas do projeto; e } \\
\text {-Relacionamentos com a Universidade de São Paulo e Universidade Federal de São Carlos. }\end{array}$ \\
\hline Empresa D & $\begin{array}{l}\text { - Além de prestar serviços de consultoria e desenvolver sistemas de automação agroindustrial, } \\
\text { oferece suporte pós-venda aos seus produtos. Suas soluções utilizam técnicas de processamento } \\
\text { digital de imagens em conjunto com projetos de hardware; } \\
\text { - Possui uma estrutura organizacional matricial balanceada; e } \\
\text { - Foi criada por pós-graduandos da Universidade de São Paulo (EESC). }\end{array}$ \\
\hline Empresa E & $\begin{array}{l}\text { - A empresa E desenvolve produtos de software para diversas finalidades. Utilizando e } \\
\text { desenvolvendo software livre dentro de seus projetos, ela emprega o compartilhamento (interno e } \\
\text { externo) de informações como forma de acelerar o desenvolvimento e aumentar a qualidade dos } \\
\text { novos softwares produzidos; } \\
\text { - Possui estrutura organizacional matricial forte. A empresa E participa de projetos internacionais } \\
\text { com equipes remotas de trabalho; e } \\
\text { - Ex-alunos e relacionamento com a Universidade Federal de São Carlos e Universidade de São } \\
\text { Paulo (EESC). }\end{array}$ \\
\hline
\end{tabular}

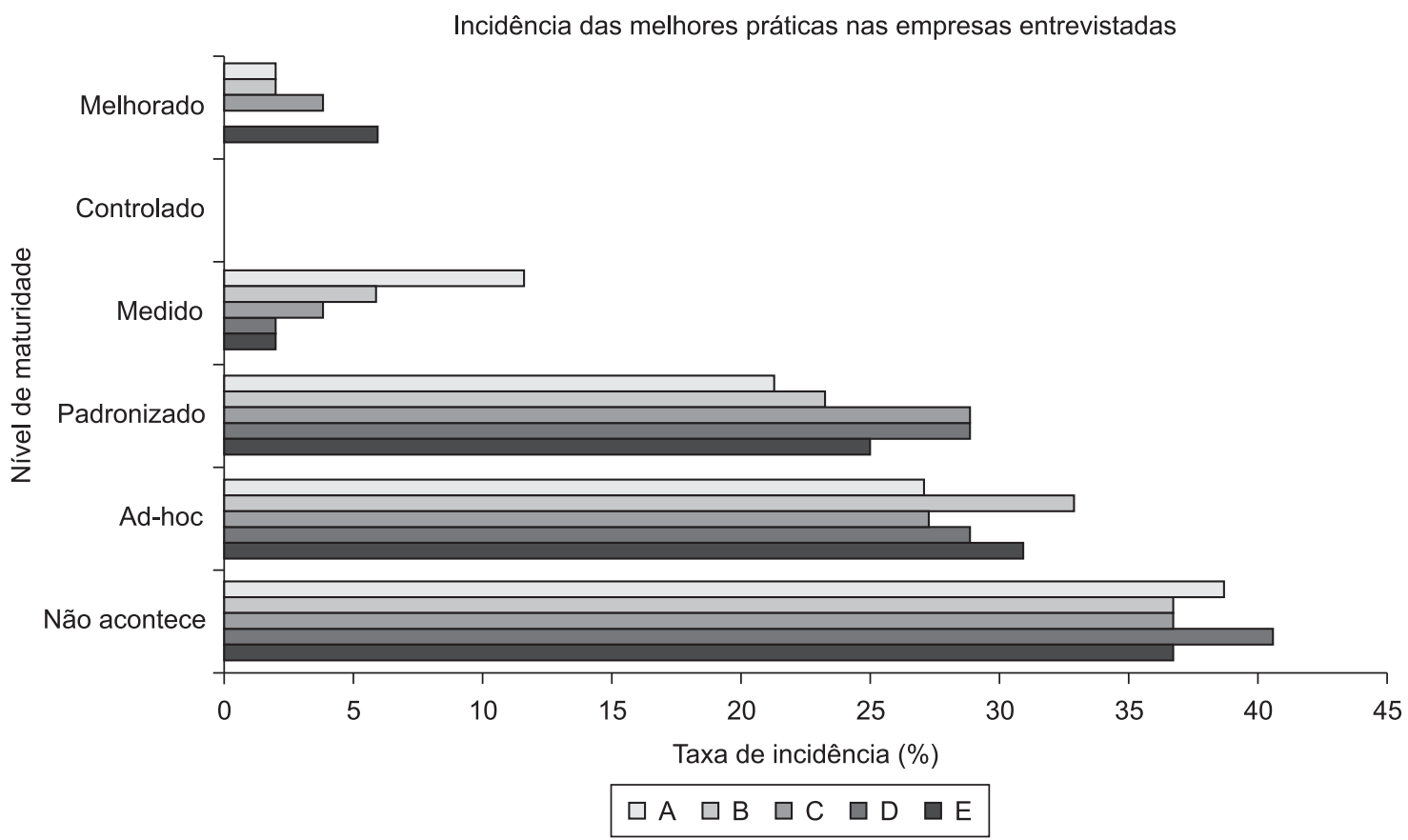

Figura 2. Comparação entre os resultados da pesquisa, por nível de maturidade. 


\section{Análise dos resultados}

As Figuras 2 e 3 resumem a avaliação das empresas por nível e categoria, respectivamente. A característica que se destaca é a ausência de práticas relacionadas à gestão de riscos do projeto. Trata-se de um aspecto interessante do levantamento, pois poderia se esperar um desempenho melhor nesta área, dado que o mapeamento de riscos e o seu controle são fundamentais para este tipo de empresa. Conforme apresentado nas seções 2 e 3, diferentemente de grandes empresas com estrutura e recursos capazes de absorver riscos inerentes aos projetos de alto

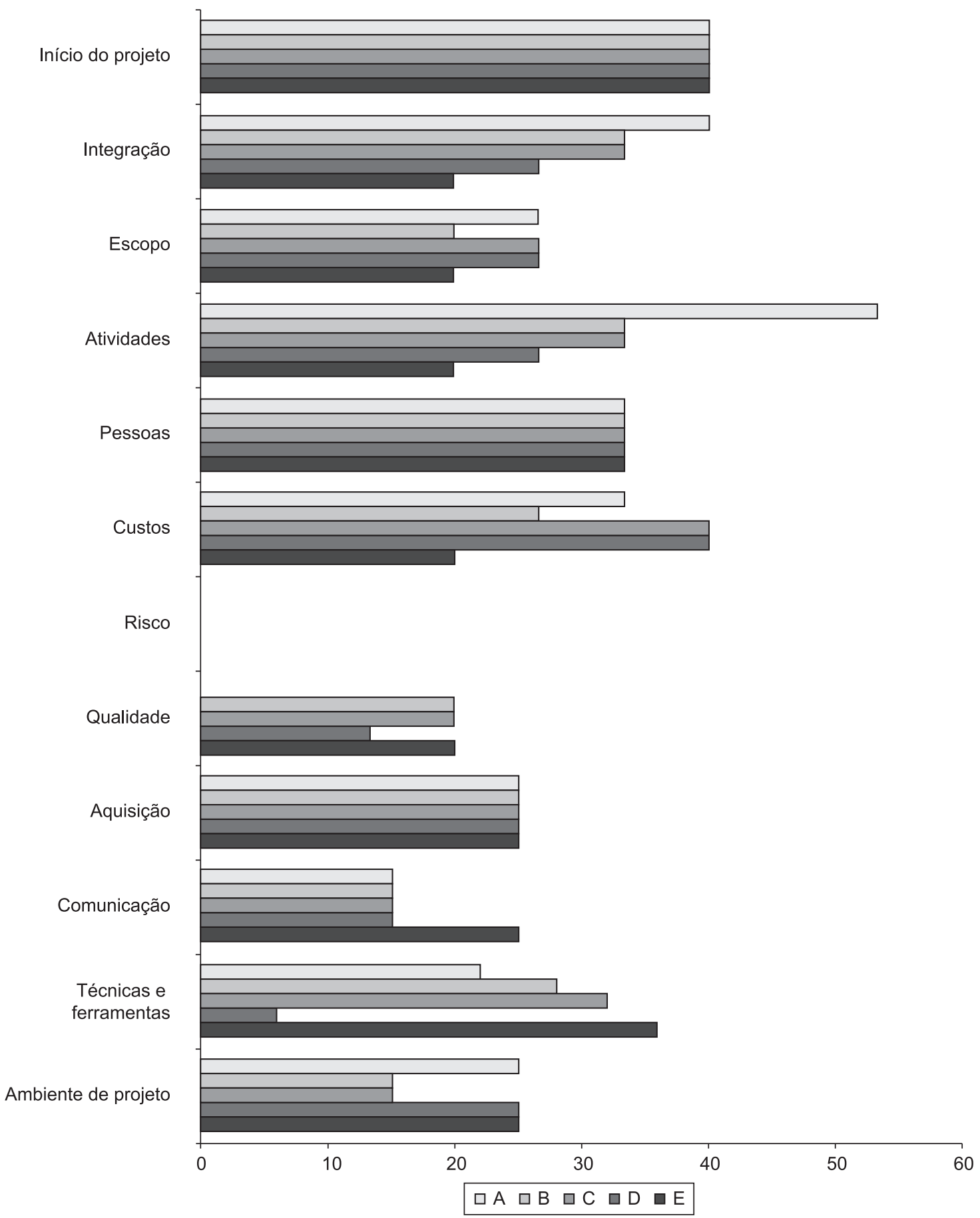

Figura 3. Comparação entre os resultados da pesquisa, por área de conhecimento. 
conteúdo tecnológico, as pequenas empresas deveriam se esmerar para diminuí-los.

As atividades que envolvem o gerenciamento de pessoas, atividades e custos são mais presentes no dia a dia dos envolvidos em projetos destas empresas. Conforme a teoria apresentada, estes resultados podem ser explicados pelas seguintes razões:

- Em todos os modelos de maturidade, a tríade custo, tempo e recursos representa o foco principal e, portanto, é natural que evoluam primeiro;

- A área de custo, principalmente, é uma das maiores preocupações de qualquer empreendedor. Visto que a gestão nestas empresas, conforme apresentado nos itens 2 e 3, depende necessariamente de bom desempenho nesta área.

Outro ponto que merece destaque é a baixa pontuação de todas as empresas no campo de gerenciamento da qualidade do projeto. Nota-se que isso não significa que a qualidade dos projetos destas empresas é ruim ou, de outra forma, melhoraria se o gerenciamento da qualidade fosse realizado conforme necessário. Na verdade, as observações de campo indicam que a proximidade com o cliente e o controle direto do empreendedor (proprietário) sobre o projeto faz uma diferença nesta área.

Isso também não quer dizer que as práticas de gestão da qualidade dos projetos seriam de todo não aplicáveis nas pequenas EBTs. A melhoria das práticas na área garantiria um padrão mais uniforme de avaliação, padronização maior nos parâmetros de controle de qualidade, rastreabilidade de problemas e a decorrente aceleração na resposta a eles. Outra vantagem seria a economia do esforço do empreendedor (proprietário), que poderia, assim, dedicar parte do seu tempo a outras tarefas como busca de novos projetos

As atividades de comunicação apresentaram uma baixa pontuação em relação às demais, apesar disso não significar, segundo as observações no campo, problemas ou dificuldades de comunicação do projeto. Isso pode ser explicado pela forte presença da informalidade na área. As boas práticas de gerenciamento de projetos ligadas à comunicação preveem itens como o planejamento da comunicação e a comunicação externa, isto é, a realização de boletins e relatórios para os interessados (stakeholders). No caso das empresas analisadas, identificou-se que o relacionamento pessoal entre os membros da equipe e o empreendedor (proprietário - gerente) e também entre este e os clientes substituíam a falta de um planejamento mais formal, relatórios de desempenho ou repositórios de documentos. Novamente, tal qual observado no item qualidade, isso não significa que estas práticas não possam ou devam ser utilizadas. A hipótese que surge do trabalho é a de que deveriam ser repensadas de forma a apropriarem-se dessa vantagem em favor das pequenas empresas.
Esta informalidade, que não pôde ser quantificada no trabalho por restrições do modelo de maturidade empregado, reflete-se também na pontuação das atividades classificadas como sendo do ambiente de projeto, dado que a estratégia e os objetivos da organização acabavam sendo transmitidos de maneira informal, por meio de discussões entre o empresário e equipes de projeto.

A Figura detalha a classificação das atividades de cada empresa entre os níveis de maturidade adotados no início da pesquisa. A primeira constatação é a grande quantidade, mais de $35 \%$ das melhores práticas sugeridas pela teoria de gerenciamento de projetos, não terem sido verificadas nas empresas analisadas; demonstra haver muito trabalho a ser feito em termos de divulgação e treinamento dos métodos de gerenciamento de projetos.

O conjunto de práticas realizadas pelas empresas de maneira não replicável ou não padronizada totaliza mais de $25 \%$. São realizadas conforme as necessidades do projeto e experiência da equipe que está na sua condução. $\mathrm{O}$ efeito são retrabalho, por exemplo, no planejamento de cada projeto, e desperdícios de melhores práticas que deixam de ser compartilhadas, principalmente com novos membros, visto que a comunicação informal soluciona em parte esse problema.

Somando os dois valores, obtém-se o número de $60 \%$ das práticas realizadas de forma não padronizada ou não realizadas pelas empresas. Considerando a amostra representativa, por ser um segmento (software) tido como de maiores exigências por parte dos clientes, emerge do trabalho a hipótese de que as empresas do Polo de Alta Tecnologia de São Carlos encontram-se em estágios iniciais de maturidade em gerenciamento de projetos. Há, portanto, um potencial significativo de melhoria para estas empresas evoluírem.

As observações realizadas indicam também um movimento consistente em direção à melhoria. Muitas estavam patrocinando treinamentos na área e aceitaram participar da pesquisa por interesse dos empreendedores (proprietários) no tema; resultado semelhante ao encontrado na pesquisa conduzida por (TOLEDO et al., 2008; JUGEND, 2006).

Por último, parte do conjunto de atividades contabilizadas como de nível melhorado (menos de $5 \%$ das atividades) faz referência ao registro e assimilação de lições aprendidas nas empresas. Explica-se este resultado, aparentemente incongruente com níveis baixos em outras áreas mais essenciais, devido às características do setor. A maioria das empresas utiliza ambientes de desenvolvimento de software (sistemas que apoiam a programação) e metodologias que obrigam o registro de configurações do produto, teste, reuso de componentes e objetos e registro de padrões. Nos casos em que isso foi observado, notadamente a empresa $\mathrm{C}$, não se verificou a passagem destas práticas em outras áreas que não as relacionadas à programação. 


\section{Conclusão}

O resultado demonstrou a viabilidade de utilização de avaliação do nível maturidade em empresas com características de EBTs, empregando-se um modelo de maturidade tradicional, no caso o OPM3. É possível aplicá-lo e ele forneceu informações do estado atual das empresas em relação às práticas de gerenciamento de projetos. O nível de maturidade das empresas estudadas, segundo a teoria, seria o inicial (Ad-Hoc). Porém, considerados os dados das observações sobre os problemas enfrentados, obtêm-se duas conclusões importantes para a teoria sobre gerenciamento de projetos.

Em primeiro lugar, o resultado indica a hipótese de haver incompatibilidades entre as necessidades e características específicas dessas empresas (com características de EBTs) e os modelos de maturidade. Os resultados nas práticas relacionadas às categorias gestão da qualidade e comunicações exemplificam. A avaliação de maturidade, segundo o modelo utilizado, critérios do OPM3, indicou níveis baixos de pontuação tanto para qualidade como para comunicação. Isso deveria significar problemas de desempenho nessas áreas. Dados da observação no campo, entretanto, demonstram o contrário. Os gestores não se queixaram de problemas relativos à qualidade e menos ainda sobre comunicação. Os problemas relatados com maior frequência pelos respondentes, e verificados pelo pesquisador em campo, eram os de controle de prazo e custos. Justamente as duas áreas sinalizadas como as de melhor prática, segundo a avaliação de maturidade realizada. Isso pode significar que o relacionamento informal e esforços pessoais do empreendedor-gestor talvez sejam suficientes para garantir boa comunicação e qualidade. E que o modelo de maturidade utilizado não foi capaz de lidar com o fenômeno.

Uma decorrência importante dessa observação é a de que seria necessário aprimorar a teoria, tanto os modelos de maturidade como as práticas de gestão de projetos. Pesquisas que revejam os métodos e os adaptem a esta realidade, na qual o papel do gerente de projetos, o empreendedor-desenvolvedor, é diferenciado. A hipótese é que sua atuação seria fundamental, pois confere gerenciamento eficiente, com práticas simples de coleta de informações e decisões: mais informais e flexíveis. Práticas não verificadas pelos modelos de maturidade atuais.

Esse resultado abre um campo de pesquisa importante, para profissionais e pesquisadores, em métodos e técnicas que possam trazer níveis mais avançados de padronização e melhoria no gerenciamento de projetos em pequenas EBTs. O efeito identificado por Tsai e Wang (2005) de diminuição da produtividade em inovação com o crescimento das pequenas empresas, pode estar relacionado a esse fenômeno. A hipótese é que os instrumentos de gestão utilizados nessas empresas, que se fundamentam nas relações pessoais, informais, que o empreendedor mantém com equipe e cliente, tornam-se ineficazes com o crescimento da empresa. Haveria então a necessidade de uma transição para uma administração mais formalizada, conforme sugerido na teoria atual de gerenciamento de projetos. $\mathrm{O}$ hiato entre essas fases criaria uma barreira ao crescimento da empresa à medida que o número e a complexidade de projetos ficam limitados às restrições de capacidade do empreendedor-gerente.

Por fim, o estudo indica similaridade da maturidade em gerenciamento de projetos entre as diferentes empresas. Há, portanto, espaço para a proposição de ações conjuntas na área de gestão de projetos, que poderiam ser lideradas por agentes de governança presentes no Polo de Alta Tecnologia de São Carlos, como o Parque de Alta Tecnologia. Para os pesquisadores, significaria a oportunidade de desenvolvimento de pesquisas que desenvolvam estruturas de escritório de projetos voltados para arranjos produtivos ou conjuntos de empresas.

\section{Referências}

ACS, Z. J.; AUDRESTCH, D. B. Small firms and entrepreneurship: an east-west perspective. Cambridge: Cambridge University Press, 1992.

ALI, A.; KRAPFEL, R.; LABAHN, D. Product innovativeness and entry strategy: impact on cycle time and break-even time. Journal of Product Innovation Management, v. 12, n. 1, p. 54-69, 1995.

CALDERINI, M.; CANTAMESSA, M. Innovation paths in product development: an empirical research. International Journal of Production Economics, v. 51, n. 1-2, p. 1-17, 1997.

CÂNDIDO, G. A.; DIAS, S. T. A. A organização das pequenas e médias empresas: o que revelam os estudos brasileiros. João Pessoa: Ed. Universitária, 1998. (Relatório de pesquisa)

CRISSIS, M. B.; KONRAD, M.; SCHRUM, S. CMMI: guidelines for process integration and product improvement. [S.1.]: Addison-Wesley Professional, 2003.

EISENHARDT, K. M. Building theories from case study research. Academy of Management Review, v. 14, n. 4, p. 532-550, 1989.

GIL, A. C. Como elaborar projetos de pesquisa. 3 ed. São Paulo: Atlas, 1991.

HICKS, D.; HEDGE, D. Highly innovative small firms in the markets for technology. Research Policy, v. 34, p. 703-716, 2005.

IBRAHIM, L.; LABRUYERE, L.; WELLS, C. Mapping table supplement to the federal aviation administrion integrated capability maturity model. 2001. Disponível em: <http:// www.faa.gov/about/office_org/headquarters_offices/aio/ library/media/v2-mapsupplement_web.pdf $>$. Acesso em: 10 jan. 2010.

JONG, J. P. J.; MARSILI, O. The fruit flies of innovations: a taxonomy of innovative small firms. Research Policy, v. 35, n. 1, p. 213-229, 2006.

JUGEND, D. Desenvolvimento de produtos em pequenas e médias empresas de base tecnológica: práticas de gestão no setor de automação de controle de processos. 2005. 2006. 125 p. Dissertação (Mestrado em Engenharia 
de Produção) - Universidade Federal de São Carlos UFSCar, São Carlos.

KERZNER, H. Gestão de Projetos: as melhores práticas. Porto Alegre: Bookman, 2006.

KNAPP \& MOORE. Integrated project method. [200-]. Disponível em: <http://www.knappandmoore.com.au/ pdf/white_paper.PDF>. Acesso em: 05 jan. 2010.

KNIGHT, G. A. Entrepreneurship and strategy in the international SME. Journal of International Management, vol. 7, n. 3, p. 155-171, 2001.

KRUGLIANSKAS, I.; RIMOLI, C. A.; SBRAGIA, R. Investigando a gestão tecnológica e o desempenho de MPEs de setores tradicionais. In: ENCONTRO DA ASSOCIAÇÃO NACIONAL DE PROGRAMAS DE PÓS-GRADUAÇÃO EM ADMINISTRAÇÃO, 20, Angra dos Reis, 1996. Anais... Angra dos Reis: ENANPAD, 1996. p. 23-25. (v. 20)

LEMOS, C. Inovação na Era do Conhecimento. In: LASTRES, H. M. M.; ALBAGLI, S. (Orgs.). Informação e globalização na era do conhecimento. Rio de Janeiro: Campus, 1999.

LEVISTKY, J. Support Systems for SME's in developing countries: a review. Vienna: UNIDO, 1996. (Discussion paper, n. 2)

MAN, T. W. Y.; LAU, T.; CHAN, K. F. The competitiveness of small and medium enterprises: a conceptualization with focus on entrepreneurial competencies. Journal of Business Venturing, v. 17, n. 2, p. 123-142, 2002.

MARCH-CHORDÀ, I.; GUNASEKARAN, A.; LLORIAARAMBURO, B. Product development process in Spanish SMEs: an emmpirical research. Technovation, v. 22, n. 5, p. 301-312, 2002.

MARCOVITCH, V.; SANTOS, S. A.; DUTRA, I. Criação de empresas com tecnologias avançadas: as experiências do PACTO/IA - FEA/USP. Revista de Administração, v. 21, n. 2, p. 3-9, 1986.

NOWAK, M. J.; GRANTHAM, C. E. The virtual incubator: managing human capital in the software industry. Research Policy, v. 29, n. 2, p. 125-134, 2000.

ORGANIZATIONAL PROJECT MANAGEMENT MATURITY MODEL - OPM3. Knowledge Foundation. Pennsylvania: Project Management Institute, 2003.

PATAH, L. A.; CARVALHO, M. M. The value of project management methodology: a case study. Product: Management and Development, v. 7, n. 2, p. 177-182, 2009. Disponível em: <http://pmd.hostcentral.com.br/search. php?busca=vol_07/nr_2>. Acesso em: 10 jan. 2010.

PROJECT MANAGEMENT BODY OF KNOWLEDGE PMBOK. Um guia do conjunto de conhecimentos em gerenciamento de projetos. 4 ed. Pensilvânia: Project Management Institute, 2008.

PORTER, M. Clusters and the New Economy of Competition. Harvard Business Review, v. 76, n. 6, p. 70-90, 1998.

RABECHINI JUNIOR, R. Competências e maturidade em gestão de projetos: uma perspectiva estruturada. 2003. 274 p. Tese (Doutorado em Engenharia de Produção) Universidade de São Paulo - USP, São Paulo.

RABECHINI JUNIOR, R.; MAXIMINIANO, A. C. A. Maturidade em gestão de projetos: análise de um caso e proposição de um modelo. In: SIMPÓSIO DE
GESTÃO DA INOVAÇÃO TECNOLÓGICA, 22, 2002 , Salvador. Anais..

RIEG, D. L.; ALVES FILHO, A. G. Esforço tecnológico e desempenho inovador das empresas do setor médicohospitalar localizadas em São Carlos, SP. Gestão \& Produção, v. 10, n. 3, p. 293-310, 2003.

ROTHWELL, R.; DODGSON, M. European technology policy evolution: convergence towards SMEs and regional technology transfer. Technovation, v. 12, n. 4, p. 223-238, 1992.

SOFTWARE ENGINEERING INSTITUTE - SEI. The Capability Maturity Model for software. Versão 2B. Pittsburgh: Carnegie Mellow University, 1997.

SOFTWARE ENGINEERING INSTITUTE - SEI. CMMI for Development. Version 1.2 (CMU/SEI-2006-TR-008). Pittsburgh: Carnegie Mellon University, 2009. Disponível em: <http://www.sei.cmu.edu/cmmi/tools/dev/>. Acesso em: 10 jan. 2010.

SPICE. Software process improvement and capability determination. [200-]. Disponível em: <http://www.sqi. gu.edu.au/spice/>. Acesso em: 10 jan. 2010.

STARBEK, M.; GRUM, J. Concurrent engineering in small companies. International Journal of Machine Tools \& Manufacture, v. 42, n. 3, p. 417-426, 2002.

STERLACCHIN, A. Do innovative activities matter to small firms in non-R\&D-intensive industries? An application to export performance. Research Policy, v. 28, n. 8, p. 819-832, 1999.

TETHER. B. S. Small and large firms: sources of unequal innovations? Research Policy, v. 27, n. 7, p. 725-745, 1998.

TOLEDO, J. C. et al. Fatores críticos de sucesso no gerenciamento de projetos de desenvolvimento de produto em empresas de base tecnológica de pequeno e médio porte. Gestão e Produção, v. 15, n. 1, p. 117-134, 2008. Disponível em: <http://www. scielo.br/scielo.php?script=sci_arttext \&pid=S0104530X2008000100011\&lng=pt\&nrm=iso $>$. Acesso em: 01 de fevereiro de 2010.

TONINI, A. C.; CARVALHO, M. M.; SPINOLA, M. M Contribuição dos modelos de qualidade e maturidade na melhoria dos processos de software. Produção, v. 18, n. 2, p. 275-286, 2008. Disponível em: <http://www. scielo.br/scielo.php?script=sci_arttext \&pid=S0103$65132008000200006 \& \operatorname{lng}=$ pt\&nrm=iso $>$. Acesso em: 01 de fevereiro de 2010.

TORKOMIAN, A. L. Estrutura de pólos tecnológicos São Carlos: EdUFSCar, 1996.

TORKOMIAN, A. L.; FERRO, J. R. A criação de pequenas empresas de alta tecnologia. Revista de Administração de Empresas, v. 2, n. 28, p. 43-50, 1988.

TSAI, K. H.; WANG, J. C. Does R\&D performance decline with firm size? A re-examination in terms of elasticity. Research Policy, v. 34, n. 6, p. 966-976, 2005.

WETERINGS, A.; KOSTER, S. Inheriting knowledge and sustaining relationships: stimulates the innovative performance of small software firms in the Netherlands? Research Policy, v. 36, n. 3, p. 320-335, 2007.

YIN, R. K. Estudo de caso: planejamento e métodos. 2 ed. Porto Alegre: Bookman, 2001. 